\title{
GESTÃO DE RISCOS NAS ATIVIDADES ECONÔMICAS VINCULADAS AO MEIO AMBIENTE NATURAL E O PRINCÍPIO DA PRECAUÇÃO EM FACE DO DIREITO AMBIENTAL CONSTITUCIONAL.
}

MANAGEMENT OF RISKS IN ECONOMIC ACTIVITIES RELATED TO THE NATURAL ENVIRONMENT, AND THE PRECAUTIONARY PRINCIPLE IN LIGHT OF CONSTITUTIONAL ENVIRONMENTAL LAW

\section{GESTIÓN DE RIESGOS EN LAS ACTIVIDADES ECONÓMICAS VINCULADAS AL MEDIO AMBIENTE NATURAL Y EL PRINCIPIO DE LA PRECAUCIÓN FRENTE AL DERECHO AMBIENTAL CONSTITUCIONAL.}

\section{Celso Antonio Pacheco Fiorillo ${ }^{1}$}

\section{Renata Marques Ferreira ${ }^{2}$}

1 É o primeiro professor Livre-Docente em Direito Ambiental do Brasil, bem como Doutor e Mestre em Direito das Relações Sociais (pela PUC/SP). DirectorAcadémico do Congresso de Derecho Ambiental Contemporáneo España/ Brasil-Universidade de Salamanca (ESPANHA) e Miembro del Grupo de Estudios Procesales de la Universidad de Salamanca - Grupo de Investigación Reconocido IUDICIUM (ESPANHA). Professor convidado visitante da Escola Superior de Tecnologia do Instituto Politécnico de Tomar (PORTUGAL) e Professor Visitante/Pesquisador da Facoltà di Giurisprudenza della Seconda Università Degli Studi di Napoli (ITALIA). Professor Permanente do Programa de Mestrado em Direito da UNINOVE-SP (BRASIL). Líder do Grupo de Pesquisa do CNPq TUTELA JURÍDICA DAS EMPRESAS EM FACE DO DIREITO AMBIENTAL CONSTITUCIONAL - UNINOVE. Advogado militante há mais de 30 anos, é Presidente da Comissão Permanente do Meio Ambiente da OAB/SP, bem como do Comitê de Defesa da Dignidade da Pessoa Humana no âmbito do Meio Ambiente Digital da Comissão de Direitos Humanos, assim como Integrante da Comissão Especial de Direito Civil da OAB/SP. Representante da OAB/SP no Conselho Gestor do Fundo Estadual de Defesa dos Interesses Difusos da Secretaria da Justiça, no Fundo Estadual para Prevenção e Remediação de Áreas Contaminadas e no Comitê da Bacia Hidrográfica do Tietê. Elaborador, coordenador e professor do Curso de Especialização de Direito Ambiental da Escola Superior de Advocacia da $\mathrm{OAB} / \mathrm{SP}$. Chanceler da Academia de Direitos Humanos. Membro Titular da cadeira 43 da Academia Paulista de Direito. Assessor científico da FAPESP, parecerista ad hoc do Centro de Estudos Judiciários do Conselho da Justiça Federal, professor efetivo da Escola de Magistratura do TRF da $3^{\text {a }}$ Região e professor da Escola Nacional de Formação e Aperfeiçoamento de Magistrados-Enfam. Professor convidado do Curso de Especialização em Engenharia Sanitária Ambiental da Universidade Mackenzie. Professor das Escolas Superiores da Magistratura Federal do RGS e dos MPs de SP, SC, MT e RJ. Elaborador/coordenador/professor do Curso de Pó- Graduação em Direito Ambiental da Escola Paulista da Magistratura-EPM. Professor MBA Direito Empresarial /FUNDACE vinculada à USP. Coordenador Científico do periódico Direito Ambiental Contemporâneo/Ed.Saraiva e membro convidado do Conselho Editorial da Revista Aranzadi de Derecho Ambiental (ESPANHA). Integrante do Comitato Scientifico do periódico Materiali e Studi di Diritto Pubblico da Seconda Universi tà Degli Studi Di Napoli bem como do Comitê Científico do Instituto Internacional de Estudos e Pesquisas sobre os Bens Comuns, com sede em Paris/FRANÇA (Institut International Etudes et de Recherches sur les Biens Communs) e Roma/ITALIA (Istituto Internazionale di Ricerca sui Beni Comuni). Membro da UCN, the International Union for Conservation of Nature.

2 Pós-Doutora em Engenharia Ambiental e Hidráulica (Contaminação e remediação de solos) - Escola Politécnica - POLI/USP. Doutora em Direito das Relações Sociais (subárea de Direitos Difusos e Coletivos-Direito Ambiental) pela Pontifícia Universidade Católica de São Paulo. Mestre em Direito das Relações Sociais (subárea de Direitos 
Resumo: Examinado em face da tutela jurídica da saúde ambiental e com fundamento teórico doutrinário alienígena adaptado a uma percepção jurídica de meio ambiente apartada da própria conceituação ampla e abrangente das quatro noções de meio ambiente estabelecidas pelo próprio Tribunal com base em perspectiva doutrinária (ADIN 3540), interpretou o Supremo Tribunal Federal ao julgar o RE 627.189 o princípio da precaução como "um critério de gestão de risco a ser aplicado sempre que existirem incertezas científicas sobre a possibilidade de um produto, evento ou serviço desequilibrar o meio ambiente ou atingir a saúde dos cidadãos, o que exige que o Estado analise os riscos, avalie os custos das medidas de prevenção e, ao final, execute as ações necessárias, as quais serão decorrentes de decisões universais, não discriminatórias, motivadas, coerentes e proporcionais". O princípio, todavia, visando à sua efetividade, obrigatoriamente necessita ser compreendido com cautela, caso a caso, à luz do princípio da legalidade e necessariamente em harmonia com a ordem jurídica do capitalismo adotada por nossa Lei Maior (Art. 1, IV e 170 e segs. da CF), particularmente em face da gestão de riscos nas atividades econômicas vinculadas ao uso dos recursos naturais/meio ambiente natural. Referido princípio, ao exigir que o Poder Público analise os riscos, avalie os custos das medidas de prevenção e, ao final, execute as ações necessárias, as quais serão decorrentes de "decisões universais, não discriminatórias, motivadas, coerentes e proporcionais", acaba por estabelecer um verdadeiro novo conteúdo exigível para instalação de obra ou atividade potencialmente causadora de significativa degradação do meio ambiente, a saber, um conteúdo sempre exigível no plano da elaboração dos estudos prévios de impacto ambiental (art. 225, parágrafo $1^{\circ}, \mathrm{IV}$ ) com a finalidade de balizar as atividades econômicas exercidas em harmonia com os princípios destinados a tornar efetiva a proteção ao meio ambiente.

Palavras-chave: Princípio da Precaução; Princípio da Legalidade; Bens ambientais; Recursos Naturais Princípio da Prevenção; Gestão de riscos; Estudo Prévio de Impacto Ambiental.

Abstract: Examined in light of the legal protection of environmental health, and with a different theoretical doctrinal foundation adapted to a legal perception of the environment, set apart from the broad and comprehensive conceptualization of the four notions of the environment established by the Court itself based on a doctrinal perspective (ADIN 3540), the Federal Supreme Court, in its ruling RE 627.189, interpreted the precautionary principle as "a risk management criterion to be applied whenever there are scientific uncertainties about the possibility of a product, event or service causing an imbalance in the environment or affecting citizens' health. This scenario requires the State to analyze the risks, assess the costs of the prevention measures and, at the end, take the necessary actions, which will result from universal, non-discriminatory, motivated, coherent and proportionate decisions. "The principle, however, aiming at its effectiveness, must necessarily be understood on a case-bycase basis, in the light of the principle of legality, and necessarily in harmony with the legal

Difusos e Coletivos-Direito Ambiental Tributário) pela Pontifícia Universidade Católica de São Paulo. Professora convidada da Escola Superior de Advocacia da Ordem dos Advogados do Brasil - Seção de São Paulo (ESA$\mathrm{OAB} / \mathrm{SP}$ ). Professora convidada do Curso de Especialização em Engenharia Sanitária Ambiental da Universidade Mackenzie. Coordenadora do Grupo de Trabalho de Tutela Jurídica da Saúde Ambiental, bem como de Tutela Jurídica da Governança Corporativa Sustentável da Comissão do Meio Ambiente da Ordem dos Advogados do Brasil-Seção de São Paulo (OAB/SP). Pesquisadora do grupo de pesquisas NOVOS DIREITOS; da Universidade Federal de São Carlos - UFSCar. Parecerista da Revista de Direito da Cidade Qualis A1-UERJ e da Revista Quaestio luris Qualis A2 - UERJ. Professora convidada do Curso de Especialização em Saneamento Ambiental da Universidade Mackenzie. Professora de Direito Ambiental Tributário do curso de extensão universitária da Escola Paulista da Magistratura. Professora Titular das Faculdades Integradas Rio Branco (Fundação Rotary). Coordenadora Científica do periódico Direito Ambiental Contemporâneo/ Editora Saraiva. 
order of capitalism adopted by our Major Law (Art. 1, IV and 170 and light of risk management in economic activities linked to the use of natural resources/the natural environment. As a matter of principle, by requiring public authorities to analyze risks, to evaluate the costs of prevention measures and, at the end, to carry out the necessary actions, resulting from "universal, non-discriminatory, motivated, coherent and proportional decisions", because it establishes a true new content required for the installation of a work or activity potentially causing significant degradation of the environment, namely, a content that is always required in drawing up previous environmental impact studies (art.225, paragraph 1, IV) with the purpose of conducting economic activities carried out in harmony with the principles intended to make effective the protection of the environment.

Keywords: Principle of Caution; Principle of Legality; Environmental goods; Natural Resources Principle of Prevention; Risk management; Environmental Impact Assessment.

Resumen:Examinadofrente a la tutelajurídica de lasalud ambientaly confundamento teórico doctrinal alienígena adaptado a una percepción jurídica de medio ambiente apartada de la propia concepción amplia y completa de las cuatro nociones de medio ambiente establecidas por el propio Tribunal con base en perspectiva doctrinal (ADIN 3540), interpretó al Supremo Tribunal Federal al juzgar al RE 627.189 el principio de la precaución como "un criterio de gestión de riesgos a aplicar siempre que existan incertidumbres científicas sobre la posibilidad de un producto, evento o servicio desequilibrar el medio ambiente o alcanzar la salud de los ciudadanos, lo que exige que el Estado analice los riesgos, evalúe los costos de las medidas de prevención y, al final, realice las acciones necesarias, que se derivarán de decisiones universales, no discriminatorias, motivadas, coherentes y proporcionadas". El principio, sin embargo, visando su efectividad, obligatoriamente necesita ser comprendido con cautela, caso por caso, a la luz del principio de la legalidad y necesariamente en armonía con el orden jurídico del capitalismo adoptado por nuestra Ley Mayor (Art. $1^{\circ}$, IV y 170 y de la CF) particularmente en vista de la gestión de riesgos en las actividades económicas vinculadas al uso de los recursos naturales / medio ambiente natural. En el caso de que el Poder Público analice los riesgos, evalúe los costos de las medidas de prevención y, al final, realice las acciones necesarias, las cuales serán derivadas de "decisiones universales, no discriminatorias, motivadas, coherentes y proporcionadas" por establecer un verdadero nuevo contenido exigible para instalación de obra o actividad potencialmente causante de significativa degradación del medio ambiente, a saber, un contenido siempre exigible en el plano de la elaboración de los estudios previos de impacto ambiental (art.225, párrafo 1, IV) la finalidad de balizar las actividades económicas ejercidas en armonía con los principios destinados a hacer efectiva la protección al medio ambiente.

Palabras clave: Principio de la Precaución; Principio de la Legalidad. Bienes ambientales; Recursos Naturales Principio de Prevención; Gestión de riesgos; Estudio Previo de Impacto Ambiental.

INTRODUÇÃO

\section{O Supremo Tribunal Federal, ao julgar o RE 627.189³, interpretou polêmico} tema vinculado à análise do direito ambiental constitucional brasileiro. Com efeito.

RE 627189 / SP - SÃO PAULO RECURSO EXTRAORDINÁRIO Relator(a): Min. DIAS TOFFOLI. Julgamento: 08/06/2016 Órgão Julgador: Tribunal Pleno Publicação. ACÓRDÃO ELETRÔNICO REPERCUSSÃO GERAL - MÉRITO DJe-066 DIVULG 31-03-2017 PUBLIC 03-04-2017. 
O Relator de referido recurso, entendendo que o assunto corresponderia "ao Tema n 479 da Gestão por Temas da Repercussão Geral do portal do STF na internet" e que "trata, à luz dos arts. 50, caput e inciso II, e 225 da Constituição Federal da possibilidade de se impor a concessionária de serviço público de distribuição de energia elétrica, por observância do princípio da precaução, a obrigação de reduzir o campo eletromagnético de suas linhas de transmissão, de acordo com padrões internacionais de segurança, em face de eventuais efeitos nocivos à saúde da população", aduziu na oportunidade que "o desafio do Supremo Tribunal Federal no julgamento de referido apelo extremo seria, dentre outros," o de verificar: i) sob a óptica constitucional, o conteúdo jurídico do princípio da precaução".

Destarte e depois de, sob sua ótica, aprofundar "a análise do conteúdo jurídico do princípio da precaução", examinando na verdade o referido "princípio" tão somente em face da tutela jurídica da saúde ambiental e com fundamento teórico doutrinário alienígena adaptado a uma percepção jurídica de meio ambiente apartada da própria conceituação ampla e abrangente das quatro noções de meio ambiente estabelecidas pelo próprio STF com base em perspectiva doutrinária (ADIN 3540), mas reconhecendo todavia que a definição do que seja "precaução", não seria absoluta sendo "pelo contrário, ainda "objeto de construção pela comunidade científica em todo o mundo (fls.10), bem como alertando que "o exagero em sua aplicação tem gerado reclamações não só na Comunidade Europeia, mas em todo o mundo" (fls.14) e por fim esclarecendo em face dos argumentos desenvolvidos em seu voto que" todos esses elementos se coadunam com as normativas e as comunicações internacionais contemporâneas, mas como já salientado, a conceituação de 'prevenção' (grifos nossos) não prescinde de outros elementos, tais como aqueles enunciados pela Comissão da União Europeia, os quais se consideram elementos essenciais para uma adequada decisão estatal"(fls.17) , enfrentou o que chamou de desafio proposto no sentido de estabelecer o conteúdo jurídico do princípio da precaução (ou prevenção?), aduzindo o que segue:

O princípio da precaução é um critério de gestão de risco a ser aplicado sempre que existirem incertezas científicas sobre a possibilidade de um produto, evento ou serviço desequilibrar o meio ambiente ou atingir a saúde dos cidadãos, o que exige que o Estado analise os riscos, avalie os custos das medidas de prevenção e, ao final, execute as ações 
necessárias, as quais serão decorrentes de decisões universais, não discriminatórias, motivadas, coerentes e proporcionais.

O Supremo Tribunal Federal, dando provimento ao recurso, entendeu por bem julgar improcedentes ambas as ações civis públicas, por maioria de votos e nos termos do voto do Relator, firmando tese destinada a estabelecer que "no atual estágio do conhecimento científico, que indica ser incerta a existência de efeitos nocivos da exposição ocupacional e da população em geral a campos elétricos, magnéticos e eletromagnéticos gerados por sistemas de energia elétrica, não existem impedimentos, por ora, a que sejam adotados os parâmetros propostos pela Organização Mundial de Saúde, conforme estabelece a Lei n 11.934/2009". Por outro lado, interpretou o conteúdo jurídico do princípio da precaução" na forma estabelecida pelo Relator, a saber:

\section{EMENTA}

Recurso extraordinário. Repercussão geral reconhecida. Direito Constitucional e Ambiental. Acórdão do tribunal de origem que, além de impor normativa alienígena, desprezou norma técnica mundialmente aceita. Conteúdo jurídico do princípio da precaução. Ausência, por ora, de fundamentos fáticos ou jurídicos a obrigar as concessionárias de energia elétrica a reduzir o campo eletromagnético das linhas de transmissão de energia elétrica abaixo do patamar legal. Presunção de constitucionalidade não elidida. Recurso provido. Ações civis públicas julgadas improcedentes. 1. O assunto corresponde ao Tema $n^{\circ} 479$ da Gestão por Temas da Repercussão Geral do portal do STF na internet e trata, à luz dos arts. $5^{\circ}$, caput e inciso II, e 225, da Constituição Federal, da possibilidade, ou não, de se impor a concessionária de serviço público de distribuição de energia elétrica, por observância ao princípio da precaução, a obrigação de reduzir o campo eletromagnético de suas linhas de transmissão, de acordo com padrões internacionais de segurança, em face de eventuais efeitos nocivos à saúde da população. 2. O princípio da precaução é um critério de gestão de risco a ser aplicado sempre que existirem incertezas científicas sobre a possibilidade de um produto, evento ou serviço desequilibrar o meio ambiente ou atingir a saúde dos cidadãos, o que exige que o estado analise os riscos, avalie os custos das medidas de prevenção e, ao final, execute as ações necessárias, as quais serão decorrentes de decisões universais, não discriminatórias, motivadas, coerentes e proporcionais. 3. Não há vedação para o controle jurisdicional das políticas públicas sobre a aplicação do princípio da precaução, desde que a decisão judicial não se 


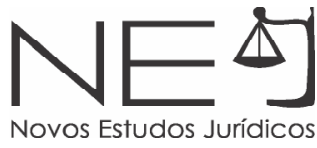

afaste da análise formal dos limites desses parâmetros e que privilegie a opção democrática das escolhas discricionárias feitas pelo legislador e pela Administração Pública. 4. Por ora, não existem fundamentos fáticos ou jurídicos a obrigar as concessionárias de energia elétrica a reduzir o campo eletromagnético das linhas de transmissão de energia elétrica abaixo do patamar legal fixado. 5. Por força da repercussão geral, é fixada a seguinte tese: no atual estágio do conhecimento científico, que indica ser incerta a existência de efeitos nocivos da exposição ocupacional e da população em geral a campos elétricos, magnéticos e eletromagnéticos gerados por sistemas de energia elétrica, não existem impedimentos, por ora, a que sejam adotados os parâmetros propostos pela Organização Mundial de Saúde, conforme estabelece a Lei n 11.934/2009. 6. Recurso extraordinário provido para o fim de julgar improcedentes ambas as ações civis públicas, sem a fixação de verbas de sucumbência.

Todavia a interpretação do conteúdo jurídico do princípio da precaução realizada pelo STF no âmbito do RE 627.189, pretendendo ser ampla e geral em face do direito ambiental constitucional, mas na verdade estabelecida em contexto específico da saúde ambiental conforme demonstrado anteriormente, merece pela oportunidade análise específica em face de cada uma das noções de meio ambiente estabelecidas pela Constituição Federal, interpretadas pela doutrina e acolhidas pelo próprio Supremo Tribunal Federal (ADI 3540), particularmente em face da tutela jurídica do meio ambiente natural.

Analisar, pois, o significado da gestão de risco em face das atividades econômicas desenvolvidas no País com o uso de recursos naturais e seus reflexos no âmbito do direito ambiental constitucional - critério estabelecido pelo STF ao interpretar o que seria o princípio da precaução - é tarefa relevante a merecer opinião jurídica.

É o que se desenvolverá no presente artigo, estruturado por meio de pesquisa realizada a partir do método hermenêutico, por meio do levantamento dos trabalhos doutrinários elaborados por estudiosos especializados atuantes no âmbito da matéria investigada e da análise jurídica vinculada ao direito ambiental constitucional, assim como das normas infraconstitucionais, tudo com o objetivo de adequar de forma satisfatória o enquadramento do tema em face do sistema jurídico constitucional em vigor e particularmente do direito ambiental constitucional. 
Para tanto se desenvolverá o tema abordando o princípio da legalidade, estruturando a interpretação do direito ambiental, a prevenção ou a precaução em face do dever de preservar os bens ambientais com fundamento na dignidade da pessoa humana (Art.1 $1^{\circ}$, III da CF), assim como nos valores sociais do trabalho e da livre iniciativa (Art.1ํ. IV e 170 e segs. da CF), o conteúdo jurídico do princípio da precaução em face de seu enquadramento no sistema constitucional em vigor, bem como da definição legal de meio ambiente, conforme interpretação estabelecida pelo Supremo Tribunal Federal (ADI 3540), as atividades de produção de bens e serviços com o uso de recursos naturais em face do princípio da precaução e o novo conteúdo exigível no EPIA (Art.225, parágrafo $1^{\circ}$, IV da CF) para instalação de obra ou atividade potencialmente causadora de significativa degradação do meio ambiente em face do aludido princípio da precaução.

\section{OS PRINCÍPIOS DO DIREITO AMBIENTAL CONSTITUCIONAL: O PRINCÍPIO DA LEGALIDADE ESTRUTURANDO A INTERPRETAÇÃO DO DIREITO AMBIENTAL CONSTITUCIONAL, ASSIM COMO OS DEMAIS PRINCÍPIOS DE DIREITO AMBIENTAL CONSTITUCIONAL.}

Como esclarece Celso Fiorillo4," "o direito ambiental é uma ciência nova, porém autônoma. Essa independência lhe é garantida porque o direito ambiental possui os seus próprios princípios diretores, presentes no art. 225 da Constituição Federal.

Vale esclarecer que o advento da Constituição proporcionou a recepção da Lei n. 6.938/81 em quase todos os seus aspectos, além da criação de competências legislativas concorrentes (incluindo as complementares e suplementares dos Municípios, previstas no art. 30, I e II, da CF), dando prosseguimento à Política Nacional de Defesa Ambiental. Esta política ganha destaque na Carta Constitucional, ao ser utilizada a expressão ecologicamente equilibrado, porquanto isso exige harmonia em todos os aspectos facetários que compõem o meio ambiente. Notase não ser proposital o uso da referida expressão (política) pela Lei n. 6.938/81, na medida em que pressupõe a existência de seus princípios norteadores.

Aludidos princípios constituem pedras basilares dos sistemas políticojurídicos dos Estados civilizados, sendo adotados no Brasil e internacionalmente

4 FIORILLO, Celso Antonio Pacheco. Curso de Direito Ambiental Brasileiro. São Paulo: Editora Saraiva, 2017 
como fruto da necessidade de uma ecologia equilibrada e indicativos do caminho adequado para a proteção ambiental, em conformidade com a realidade social e os valores culturais de cada Estado.

Claro está, pois, que o direito ambiental brasileiro tem sua gênese fixada na Lei Maior, sendo estruturado em decorrência dos comandos por ela estabelecidos.

Daí a necessidade de destacar o PRINCÍPIO DA LEGALIDADE, indicado explicitamente no art. $5^{\circ}$, II, da Carta Magna como ponto de partida fundamental no sentido de interpretar de forma adequada a efetividade de todos os princípios do direito ambiental estruturados na Carta Magna.

Trata-se, mais que o critério superficial usado pelo STF na oportunidade de apreciação do RE 627.189, de necessariamente observar na aplicação do direito ambiental brasileiro o princípio chamado por Pontes de Miranda de "legalitariedade"5, a saber, "qualquer regra jurídica que crie dever de ação positiva (fazer) ou de ação negativa (deixar de fazer, abster-se) tem de ser regra de lei com as formalidades que a Constituição exige", ou seja, "ninguém, brasileiro ou estrangeiro, pode ser compelido a fazer, a deixar de fazer ou a tolerar que se faça alguma coisa, senão em virtude de lei", como adverte José Celso de Mello Filho ${ }^{6}$.

Para os efeitos do referido princípio, "lei é todo ato normativo editado, ordinariamente, pelo Poder Legislativo, ou, excepcionalmente, pelo Poder Executivo (leis delegadas e decretos-lei), no desempenho de sua competência constitucional e segundo o rito estabelecido na própria Constituição. Apenas a lei em sentido formal, portanto, pode impor às pessoas um dever de prestação ou abstenção. Normas infralegais, ainda que veiculadoras de regras gerais, impessoais e abstratas, não atendem à exigência constitucional", ou seja, pelo princípio da legalidade", "fica certo que qualquer comando jurídico impondo comportamentos forçados há de provir de uma das espécies normativas devidamente elaboradas conforme as regras de processo legislativo constitucional" como recorda Alexandre de Moraes ${ }^{7}$.

O próprio Supremo Tribunal Federal fixou comando didático no que se refere à preponderância e à predominância de referido princípio EXPLICITAMENTE indicado no Art.5' ${ }^{\circ}$ II da Lei Maior, a saber:

$5 \quad$ MIRANDA, Pontes Comentários à Constituição de 1967 com a emenda número 1 de 1969. Rio de Janeiro: Forense, 1967.

6 MELLO FILHO, José Celso Constituição Federal Anotada São Paulo; Editora Saraiva, 1986.

7 MORAES, Alexandre Direito Constitucional São Paulo: Atlas, 2011 
- O princípio da reserva de lei atua como expressiva limitação constitucional ao poder do Estado, cuja competência regulamentar, por tal razão, não se reveste de suficiente idoneidade jurídica que Ihe permita restringir direitos ou criar obrigações. Nenhum ato regulamentar pode criar obrigações ou restringir direitos, sob pena de incidir em domínio constitucionalmente reservado ao âmbito de atuação material da lei em sentido formal. [AC $1.033 \mathrm{AgR}-\mathrm{QO}$, rel. min. Celso de Mello, j. 25-5-2006, P, DJ de 16-6-2006.]

O princípio constitucional da reserva de lei formal traduz limitação ao exercício das atividades administrativas e jurisdicionais do Estado. A reserva de lei - analisada sob tal perspectiva - constitui postulado revestido de função excludente, de caráter negativo, pois veda, nas matérias a ela sujeitas, quaisquer intervenções normativas, a título primário, de órgãos estatais não legislativos. Essa cláusula constitucional, por seu sumário 66 Art. 50, II vez, projeta-se em uma dimensão positiva, eis que a sua incidência reforça o princípio, que, fundado na autoridade da Constituição, impõe à administração e à jurisdição a necessária submissão aos comandos estatais emanados, exclusivamente, do legislador. [ADI $2.075 \mathrm{MC}$, rel. min. Celso de Mello, j. 7-2-2001, P, DJ de 27-6-2003.

- A inobservância ao princípio da legalidade pressupõe o reconhecimento de preceito de lei dispondo de determinada forma e provimento judicial em sentido diverso, ou, então, a inexistência de base legal e, mesmo assim, a condenação a satisfazer o que pleiteado. [AI 147.203 AgR, rel. min. Marco Aurélio, j. 18-5-1993, 2a T, DJ de 116-1993.

Destarte, resta evidente que o princípio da legalidade, ao estruturar o direito ambiental constitucional brasileiro, determina os superiores critérios destinados a organizar no plano superior normativo os demais princípios específicos do direito ambiental constitucional brasileiro.

\section{PREVENÇÃO OU PRECAUÇÃO: ORIENTAÇÃO NORMATIVA POLÍTICA OU JURÍDICA? O ART.225 DA CONSTITUIÇÃO FEDERAL E O DEVER DE PRESERVAR OS BENS AMBIENTAIS COM FUNDAMENTO NA DIGNIDADE DA PESSOA HUMANA (ART.1, III DA CF), ASSIM COMO NOS VALORES SOCIAIS DO TRABALHO E DA LIVRE INICIATIVA (ART.1ํ, IV E 170 E SEGS. DA CF).}

Conforme esclarece Celso Fiorillo, "nossa Constituição Federal de 1988 expressamente adotou o princípio da prevenção, ao preceituar, no caput do 


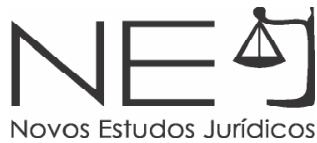

art. 225, o dever do Poder Público e da coletividade de proteger e preservar os bens ambientais de uso comum do povo, de natureza difusa, para as presentes e futuras gerações".

Trata-se de evidenciar, conforme lição de Nelson Nery $\mathrm{Jr}^{8}$., o princípio da prevenção (Vorbeugungsprinzip) como "de atuação indispensável no domínio do ambiente" e que "tem por escopo evitar a ocorrência de danos ambientais irreversíveis, cientificamente comprovados".

Destarte, o comando constitucional, em face do princípio da legalidade, determina claramente a necessidade de preservar os bens ambientais destinados ao seu uso comum, evidentemente em harmonia com os fundamentos (art. $1^{\circ}$ da CF), bem como objetivos (art. $3^{\circ}$ da CF) explicitados como princípios constitucionais destinados a interpretar não só o direito constitucional como evidentemente o direito ambiental constitucional brasileiro.

Qual seria então o escopo da norma constitucional estabelecida no Art.225? Prevenção ou Precaução?

Com efeito.

Ao tratar da denominada proteção internacional do Meio Ambiente, Accioly, Silva e Casella ${ }^{9}$, citando as conferências de Estocolmo (1972), Rio (1992) e Johannesburgo (2002), explicam a origem do termo precaução no Princípio 15 da Declaração do Rio de Janeiro sobre Meio Ambiente e Desenvolvimento (“Com o fim de proteger o meio ambiente, o princípio da precaução deverá ser amplamente observado pelos Estados, de acordo com suas capacidades. Quando houver ameaça de danos graves ou irreversíveis, a ausência de certeza científica absoluta não será utilizada como razão para o adiamento de medidas economicamente viáveis para prevenir a degradação ambiental"), destacando que tradicionalmente os tratados ambientais costumavam ser não precaucionários. Espécies ameaçadas só seriam protegidas se houvesse prova científica da sua ameaça, assim como atividades poluentes só seriam consideradas degradantes se provada de forma concreta a relação de causalidade entre o dano e a atividade. Tal cenário começou a mudar com o início das negociações para a Convenção

8 NERY JR, Nelson Constituição Federal comentada e legislação constitucional, São Paulo: Revista dos Tribunais,2009.

9 ACCIOLY, SILVA e CASELLA Manual de Direito Internacional Público São Paulo; Saraiva, 2009. 
de Viena para a proteção da Camada de Ozônio, de 1985, quando incertezas científicas poderiam impedir a adoção de medidas voltadas à restrição da produção e comercialização de gases que destroem a camada de ozônio.

Falta de comprovação científica sempre foi argumento para retardar ações de preservação do meio ambiente ou mesmo para impedi-las. A partir da década de 1980, vários tratados e documentos passaram a fazer referência a tal princípio, muitas vezes de forma quase confundida com deveres gerais de prevenção de danos (grifos nossos). De qualquer forma, o princípio da precaução, representado pelo Princípio 15 da Declaração do Rio, também sofre de incipiente especificação de conteúdo normativo (grifos nossos). Na forma como conhecida hoje, o princípio apenas se limita a afirmar que a falta de certeza científica não deve ser usada como meio de postergar a adoção de medidas preventivas, quando houver ameaça séria de danos irreversíveis.

Daí se extrai orientação normativa, antes política que jurídica (grifos nossos). Não se pode dizer, com base exclusivamente neste princípio, qual a conduta a ser tomada ante a ocorrência da atividade concreta que tenha potencial de degradação irreversível do meio ambiente. Deste se obtém somente mandamento para a tomada de iniciativas de precaução, seja por parte do estado, dos Parlamentos ou da própria comunidade internacional, ainda que o risco de dano não possa ser cientificamente demonstrado.

Esse princípio foi objeto de algumas decisões internacionais, em especial no âmbito da OMC, mas seu status jurídico - se soft Law, princípio geral de direito ou norma consuetudinária - permanece incerto.

De fato, como esclarece TeresaAncona Lopes, o "princípio" antes mencionado estaria dentro de uma proposta mais ampla destinada a gerenciar ou atenuar riscos de dano na chamada sociedade de riscos ${ }^{10}$, sendo certo que teria sido introduzido pelo direito ambiental alemão na década de 70 com vistas à proteção ambiental - é o Vorsorgeprinzip.

Para Nelson Nery Jr., o princípio da precaução (Vorsorgegrundsatz) "referese ao conteúdo e a intensidade de proteção ambiental. Significa que a política do 


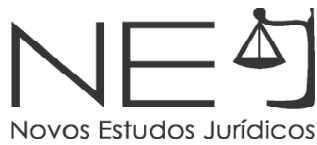

ambiente não se limita à eliminação ou redução da poluição já existente ou iminente, mas assegura que a poluição é combatida na sua incipiência e que os recursos naturais são utilizados numa base de produção sustentada. Este princípio reveste-se de vários aspectos diferentes, tais como a manutenção da poluição a um nível tão baixo quanto possível, a redução dos materiais residuais, a proibição da deteriorização significativa do ambiente, a redução dos riscos conhecidos, mas muito improváveis"11.

No entanto, adverte o professor, "essa concepção de precaução é evidentemente irrealista e perigosa, na medida em que sua aplicação provoca o risco de conduzir a uma paralisia total da atividade econômica". ${ }^{12}$

De qualquer forma, e retomando a interpretação de Teresa Ancona Lopes "o princípio da precaução está colocado dentro do princípio da prevenção (grifos nossos) e ambos fazem parte da prudência ${ }^{13}$.

Destarte importar a cultura alienígena, com argumentos antes políticos que jurídicos, na feliz expressão de Accioly, Silva e Casella, seria desenvolver no plano constitucional brasileiro uma diferença entre prevenção e precaução sem qualquer fundamento no princípio da legalidade violando a necessária harmonia existente no sistema constitucional ambiental, estruturado no dever de preservar os bens ambientais destinados ao uso de brasileiros e estrangeiros residentes no País, com fundamento na dignidade da pessoa humana (Art. $1^{\circ}$, III da CF), assim como nos valores sociais do trabalho e da livre iniciativa (Art.10, IV e 170 e segs. da CF).

Todavia, a interpretação do conteúdo jurídico do princípio da precaução estabelecida no RE 627.189 merece ser desenvolvida visando ser ajustada ao ordenamento jurídico constitucional.

\section{O CONTEÚDO JURÍDICO DO PRINCÍPIO DA PRECAUÇÃO EM FACE DE SEU ENQUADRAMENTO NO SISTEMA CONSTITUCIONAL EM VIGOR E A AVALIAÇÃO DOS CUSTOS DAS MEDIDAS DE PREVENÇÃO (OU PRECAUÇÃO?).}

O princípio da precaução, conforme estabelecido pelo Supremo Tribunal Federal no âmbito do contexto em que foi interpretado (RE 627.189), "é um

11 NERY Junior, Nelson Constituição Federal comentada e legislação constitucional São Paulo: Revista dos Tribunais, 2009

12 NERY Junior, Nelson Constituição Federal comentada e legislação constitucional São Paulo: Revista dos Tribunais, 2009.

13 ANCONA LOPES, Teresa Princípio da Precaução e Evolução da Responsabilidade Civil, Tese para Concurso de Professor Titular de Direito Civil da Faculdade de Direito da Universidade de São Paulo, 2008. 
critério de gestão de risco a ser aplicado sempre que existirem incertezas científicas sobre a possibilidade de um produto, evento ou serviço desequilibrar o meio ambiente ou atingir a saúde dos cidadãos, o que exige que o Estado analise os riscos, avalie os custos das medidas de prevenção e, ao final, execute as ações necessárias, as quais serão decorrentes de decisões universais, não discriminatórias, motivadas, coerentes e proporcionais".

Destarte, sempre que existirem incertezas científicas sobre a possibilidade de um produto, evento ou serviço para desequilibrar o meio ambiente ou atingir a saúde dos cidadãos, incide o denominado princípio da precaução. Trata-se, na perspectiva do STF, de "critério de gestão de risco" a ser exigido do Estado que deverá analisar os referidos riscos, avaliar os custos das medidas de prevenção (ou precaução?) e executar as ações necessárias "que deverão ser decorrentes de decisões universais, não discriminatórias, motivadas, coerentes e proporcionais".

Verifica-se, pois, que o conteúdo jurídico do princípio da precaução no âmbito do contexto que foi interpretado (RE 627.189), bem como a avaliação dos custos das medidas de prevenção (ou precaução?), estabelecido em referido conteúdo, só pode ser adequadamente compreendido em face de necessária e preliminar interpretação sistemática das noções de meio ambiente existentes na Carta Magna e evidentemente em contexto econômico delimitado pelo sistema normativo superior. Senão, veja-se.

O PRINCÍPIO DA PRECAUÇÃO EM FACE DA DEFINIÇÃO LEGAL DE MEIO AMBIENTE E SEUS REFLEXOS NA ORDEM ECONÔMICA CAPITALISTA: 0 CONCEITO AMPLO E ABRANGENTE DAS NOÇÕES DE MEIO AMBIENTE NATURAL, DE MEIO AMBIENTE CULTURAL, DE MEIO AMBIENTE ARTIFICIAL (ESPAÇO URBANO) E DE MEIO AMBIENTE LABORAL CONFORME INTERPRETAÇÃO ESTABELECIDA PELO SUPREMO TRIBUNAL FEDERAL E A ADI 3540.

O legislador infraconstitucional, ao tratar de definir juridicamente o meio ambiente, conforme se verifica no art. $3^{\circ}$, I, da Lei n. 6.938/81 (a Lei da Política Nacional do Meio Ambiente), estabeleceu o que segue:

"Art. $3^{2}$ Para os fins previstos nesta Lei, entende-se por: 
I - meio ambiente, o conjunto de condições, leis, influências e interações de ordem física, química e biológica, que permite, abriga e rege a vida em todas as suas formas".

Referido conceito foi integralmente recepcionado pela Carta Magna que buscou tutelar não só o meio ambiente natural, mas também o artificial, o cultural e o do trabalho em face de interpretação sistemática desenvolvida pela doutrina ${ }^{14}$, o que levou o Supremo Tribunal Federal a ratificar referida visão doutrinária, conforme ADI 3540, a saber:

"A atividade econômica não pode ser exercida em desarmonia com os princípios destinados a tornar efetiva a proteção ao meio ambiente. A incolumidade do meio ambiente não pode ser comprometida por interesses empresariais nem ficar dependente de motivações de índole meramente econômica, ainda mais se se tiver presente que a atividade econômica, considerada a disciplina constitucional que a rege, está subordinada, dentre outros princípios gerais, àquele que privilegia a 'defesa do meio ambiente' (CF, art. 170, VI), que traduz conceito amplo e abrangente das noções de meio ambiente natural, de meio ambiente cultural, de meio ambiente artificial (espaço urbano) e de meio ambiente laboral. Doutrina (grifos nossos) Os instrumentos jurídicos de caráter legal e de natureza constitucional objetivam viabilizar a tutela efetiva do meio ambiente, para que não se alterem as propriedades e os atributos que Ihe são inerentes, o que provocaria inaceitável comprometimento da saúde, segurança, cultura, trabalho e bem-estar da população, além de causar graves danos ecológicos ao patrimônio ambiental, considerado este em seu aspecto físico ou natural" (ADI 3.540-MC, Rel. Min. Celso de Mello, julgamento em 1ㅇ-92005, Plenário, DJ de 3-2-2006)."

Assim é fácil perceber que, na orientação estabelecida pelo próprio Supremo Tribunal Federal, em 2006 (ADI 3540), não só a atividade econômica não pode ser exercida em desarmonia com os princípios destinados a tornar efetiva a proteção ao meio ambiente, como efetivamente não existe um único conceito jurídico de meio ambiente, mas, pelo menos, quatro conceitos (meio ambiente natural, meio ambiente cultural, meio ambiente artificial e meio ambiente laboral), ou seja,

14 OsquatrosignificativosaspectosmencionadosjáeramindicadosporCelsoFiorillodesdea $1^{\mathrm{a}}{ }^{\mathrm{e}}$ ediçãodeseu Curso(2000). FIORILLO, Celso Antonio Pacheco Curso de Direito Ambiental Brasileiro São Paulo: Editora Saraiva 2000. 
noções estabelecidas pela própria Carta Magna e desenvolvidas pela doutrina especializada há pelo menos 30 anos...

Todavia, ao estabelecer em 2017 (RE 627.189) o que seria conteúdo normativo da precaução, como mais um dos princípios ambientais constitucionais existentes e evidentemente no âmbito do contexto em que foi interpretado a saber, diante do caso concreto que interpretou vinculado ao meio ambiente natural e saúde, estabeleceu o julgado do Supremo Tribunal Federal a necessidade de melhor compreender a matéria no plano do uso dos recursos naturais/meio ambiente natural em face das atividades econômicas asseguradas constitucionalmente aos empreendedores em harmonia com ordem jurídica do capitalismo adotada pela Lei Maior (Art.1ํ. IV e 170 e segs. da CF).

\section{PRINCÍPIO DA PRECAUÇÃO EM FACE DA ORDEM ECONÔMICA CONSTITUCIONAL.}

Conforme destacam Celso Fiorillo e Renata Ferreira ${ }^{15}$, "a ordem econômica estabelecida no plano normativo constitucional, fundada na valorização do trabalho humano e na livre iniciativa, tem por fim assegurar a todos existência digna, conforme os ditames da justiça social, observados alguns princípios indicados nos incisos do Art.170". Dentre os princípios antes referidos, está o da defesa do meio ambiente (Art. 170, VI da CF), cujo conteúdo constitucional está descrito no Art. 225 da CF, inclusive mediante tratamento diferenciado conforme o impacto ambiental (Art. 225, parágrafo $1^{\circ}$, IV) dos produtos e dos serviços e de seus processos de elaboração e prestação.

Claro está que o critério interpretativo imposto pela Constituição Federal no que se refere à implementação do referido princípio da defesa do meio ambiente, como um dos princípios da atividade econômica, encontra seu necessário fundamento não só em decorrência no Art. $1^{\circ}$ e tem como objetivo o conteúdo estabelecido pelo Art. $3^{\circ}$ da Constituição Federal. Assim a defesa do meio ambiente, embora adote como causa primária no plano normativo os valores sociais do trabalho e da livre iniciativa (Art.1 ${ }^{\circ}$, IV), necessita respeitar a dignidade da pessoa humana como superior fundamento constitucional (Art.1 ${ }^{\circ}$,

15 FIORILLO, Celso Antonio Pacheco; FERREIRA, Renata Marques. Tutela Constitucional da Defesa do Meio Ambiente como Princípio da Atividade Econômica em face do denominado desenvolvimento sustentável. Novos Estudos Jurídicos, [S.I.], v. 22, n. 2, p. 461-488, ago. 2017. ISSN 2175-0491. 


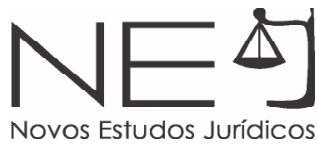

III). Por outro lado, a defesa do meio ambiente tem objetivos definidos no plano constitucional com particular destaque à construção de uma sociedade livre, justa e solidária (Art. $\left.3^{\circ}, \mathrm{I}\right)$, garantir o desenvolvimento nacional (Art.3 II) e particularmente, em face da realidade brasileira, erradicar a pobreza e a marginalização e reduzir as desigualdades sociais e regionais (Art. $3^{\circ}$, III)".

Assim, fica evidente que o denominado princípio da precaução jamais teria o condão de eliminar a ordem econômica prevista na Constituição de 1988 que "define opção por um sistema, o capitalista, no qual joga um papel primordial a livre iniciativa", conforme decidido pelo Supremo Tribunal Federal ${ }^{16}$.

Destarte, o critério de gestão de risco a ser aplicado sempre que existirem incertezas científicas sobre a possibilidade de um produto, evento ou serviço desequilibrar o meio ambiente ou atingir a saúde dos cidadãos, exigindo do Estado a análise dos riscos, avaliação dos custos das medidas de prevenção e, ao final, execução das ações necessárias, as quais serão decorrentes de decisões universais, não discriminatórias, motivadas, coerentes e proporcionais (princípio da precaução), será observado caso a caso, mas SEMPRE em face do balizamento constitucional da ordem econômica capitalista em obediência aos fundamentos constitucionais anteriormente aludidos.

No que se refere aos recursos naturais/meio ambiente natural, caberia ainda observar algumas especificidades.

\section{O USO DOS BENS AMBIENTAIS NA ORDEM JURÍDICO ECONÔMICA DO CAPITALISMO EM FACE DO PRINCÍPIO DA PRECAUÇÃO: A GESTÃO DOS RECURSOS NATURAIS NO ÂMBITO DAS ATIVIDADES ECONÔMICAS EM FACE DO DIREITO AMBIENTAL CONSTITUCIONAL.}

Conforme o Supremo Tribunal Federal já teve oportunidade de estabelecer de forma didática, "é certo que a ordem econômica na Constituição de 1988 define opção por um sistema, o capitalista, no qual joga um papel primordial a livre iniciativa. Essa circunstância não legitima, no entanto, a assertiva de que o Estado só intervirá na economia em situações excepcionais. Muito ao contrário" (ADI 1950/SP - São Paulo Ação Direta de Inconstitucionalidade

$\overline{16}$ ADI 1950 / SP - SÃO PAULO AÇÃO DIRETA DE INCONSTITUCIONALIDADE Relator (a): Min. EROS GRAU Julgamento: 03/11/2005 Tribunal Pleno Publicação DJ 02-06-2006 
Relator(a): Min. Eros Grau Julgamento: 03/11/2005 Tribunal Pleno Publicação DJ 02-06-2006). Com efeito.

Ligado o plano das atividades econômicas à tutela jurídica do meio ambiente, a gestão dos recursos naturais, vinculada que está ao uso dos bens ambientais, deve também ser necessariamente considerada no plano da ordem econômica capitalista estabelecida pela Lei Maior.

Assim, o uso dos recursos naturais brasileiros, por força do que determina o sistema normativo constitucional em vigor, deve ser gerenciado em face de uma economia baseada "na separação entre trabalhadores juridicamente livres, que dispõem apenas da força de trabalho e a vendem em troca de salário, e capitalistas, os quais são proprietários dos meios de produção e contratam os trabalhadores para produzir mercadorias (bens dirigidos para o mercado) visando à obtenção de lucro", conforme lição de Paulo Sandroni ${ }^{17}$. Com efeito.

Ao assegurar a todos o livre exercício de qualquer atividade econômica, independentemente de autorização de órgãos públicos, salvo nos casos previstos em lei (parágrafo único do art. 170 da CF), a Constituição Federal destacou de forma importante a necessidade de se interpretar no plano normativo o significado de referido conceito de atividade em face de seus evidentes reflexos em toda a ordem econômica constitucional particularmente em decorrência do direcionamento estabelecido pelos próprios princípios gerais da atividade econômica (Título VII - Da Ordem Econômica e Financeira - Capítulo I - Dos Princípios Gerais da Atividade Econômica).

Não se trata de pura e simplesmente compreender a atividade em face tão somente da economia, a saber, dentro do termo economia, lembrando Antonio Dias Leite ${ }^{18}$, como o "quadro físico e institucional dentro do qual se realizam as atividades de produção de bens e serviços requeridos pela sociedade, bem como sua evolução no tempo", mas de compreender de que forma "as atividades de produção de bens e serviços requeridos pela sociedade" têm seu balizamento fixado pela Constituição Federal.

17 SANDRONI, Paulo Novíssimo Dicionário de Economia São Paulo: Editora Best Seller, 1999

18 LEITE, Antonio Dias Leite A Economia Brasileira - de onde viemos e onde estamos". Rio de Janeiro: Elsevier, 2011. 
Trata-se, a rigor, como lembra Celso Fiorillo e Renata Ferreira ${ }^{19}$, de verificar o que significa atividade no contexto econômico normativo constitucional lembrando, de forma evidentemente menos ampla, dentro de análise doutrinária jurídica e em contexto infraconstitucional, ser a atividade "conceito básico de direito comercial, fenômeno essencialmente humano" (Bonfante, Lezioni di storia del commercio). E hoje se pode afirmar que é conceito básico de direito empresarial. A empresa se realiza pela atividade, como o sujeito se realiza por seus atos. Tanto o ato quanto a atividade se exteriorizam por meio de negócios jurídicos, de tal sorte que se afirma que o contrato é o núcleo básico da atividade empresarial (Bulgarelli, Contratos mercantis, p. 25).

Todavia, atribuindo ao termo posição juridicamente superior, vale destacar que a Constituição Federal passou a entender a partir de 1988 ser a atividade no plano normativo econômico descrito na Lei Maior conceito bem mais amplo, abarcando não só comerciais e empresariais, mas também e particularmente indicando a atividade em face da defesa do meio ambiente, o que significa compreender a matéria ora desenvolvida, como já salientado anteriormente, em face do conceito amplo e abrangente das noções de meio ambiente natural, de meio ambiente cultural ${ }^{20}$, de meio ambiente artificial (espaço urbano) e de meio ambiente laboral. Com efeito.

Entendida como "qualidade; faculdade ou possibilidade de agir, de se mover, de fazer, empreender coisas; exercício dessa faculdade, ação" ${ }^{21}$ em face do que se admite ser ativo ("que exerce ação, que age, que tem a faculdade de agir" $)^{22}$, o termo atividade também pode ser perfeitamente explicado no âmbito da economia (atividade econômica) como a faculdade de empreender coisas, o que facilita evidentemente seu entendimento no contexto da ordem econômica constitucional com evidentes reflexos no direito ambiental constitucional, ou seja, a livre iniciativa passa a atuar em absoluta sintonia com os princípios fundamentais do direito ambiental constitucional.

19 FIORILLO, Celso Antonio Pacheco FERREIRA, Renata Marques Tutela Jurídica do Patrimônio Cultural Brasileiro em face do Direito Ambiental Constitucional Rio de Janeiro: Lumen Juris, 2018

20 Nele incluído o Meio Ambiente Digital. FIORILLO, Celso Antonio Pacheco. O Marco Civil da Internet e o Meio Ambiente Digital na Sociedade da Informação, São Paulo: Saraiva, 2015; FIORILLO, Celso Antonio Pacheco. Princípios constitucionais do direito da sociedade da informação, São Paulo: Saraiva, 2014; FIORILLO, Celso Antonio Pacheco. Crimes no Meio Ambiente Digital em face da Sociedade da Informação São Paulo: Ed. Saraiva, 2016.

21 Dicionário Houaiss fls.215.

22 Dicionário Houaiss fls.215. 
Assim, reiterando matéria já aduzida anteriormente, "é certo que a ordem econômica na Constituição de 1988 define opção por um sistema no qual joga um papel primordial a livre iniciativa. Essa circunstância não legitima, no entanto, a assertiva de que o Estado só intervirá na economia em situações excepcionais".

Destarte, no plano superior constitucional em vigor (princípio fundamental), a livre iniciativa (Art. $1^{\circ}$,IV da CF) como "princípio do liberalismo econômico que defende a total liberdade do indivíduo para escolher e orientar sua ação econômica, independentemente da ação de grupos sociais ou do Estado, implicando em "total garantia da propriedade privada, o direito de o empresário investir seu capital no ramo que considerar mais favorável e fabricar e distribuir os bens produzidos em sua empresa da forma que achar mais conveniente à realização dos lucros", conforme explicação de Paulo Sandroni ${ }^{23}$, deixa de ser observada em face de sua interpretação inicial e passa a ser admitida em contexto de evidente equilíbrio.

Daí a existência de princípios ambientais constitucionais como os observados nos incisos do Art.170 sendo certo que, dentre os referidos princípios, está exatamente o da defesa do meio ambiente natural, cultural, artificial e do trabalho (Art.170, VI da CF), cujo conteúdo constitucional está descrito no Art. 225 da CF, inclusive mediante tratamento diferenciado, conforme o impacto ambiental (Art.225, parágrafo $1^{\circ}$, IV) dos produtos e dos serviços e dos seus processos de elaboração e prestação.

Por via de consequência, ao assegurar a todos o livre exercício de qualquer atividade econômica, a Constituição Federal condiciona o exercício da referida atividade no plano normativo à defesa do meio ambiente natural, do meio ambiente cultural, do meio ambiente artificial (espaço urbano) e do meio ambiente laboral, tudo em face dos princípios do direito ambiental constitucional na forma de suas respectivas tutelas jurídicas constitucionais.

Os recursos naturais/meio ambiente natural têm, pois, sua gestão estabelecida em face da ordem econômica definida na Constituição Federal submetendose evidentemente aos princípios do direito ambiental constitucional e dentre eles ao denominado princípio da precaução no âmbito do contexto em que foi interpretado pelo Supremo Tribunal Federal no RE 627189.

23 SANDRONI, Paulo Sandroni. Dicionário de Economia do Século XXI. Rio de Janeiro/São Paulo, Editora Record, 2005 


\section{ATIVIDADES DE PRODUÇÃO DE BENS E SERVIÇOS COM O USO DE RECURSOS NATURAIS EM FACE DO PRINCÍPIO DA PRECAUÇÃO: INCERTEZAS CIENTÍFICAS SOBRE A POSSIBILIDADE DE UM PRODUTO, EVENTO OU SERVIÇO DESEQUILIBRAR O MEIO AMBIENTE OU ATINGIR A SAÚDE DOS CIDADÃOS E DAS EXIGÊNCIAS ATRIBUÍDAS AO ESTADO.}

O princípio da precaução, no âmbito do contexto em que foi interpretado pelo Supremo Tribunal Federal no RE 627189, é um critério de gestão de risco exigível a ser aplicado sempre que existirem incertezas científicas sobre a possibilidade de um produto, evento ou serviço desequilibrar o meio ambiente ou atingir a saúde dos cidadãos. Seria, pois, uma avaliação do risco (aspectos positivos e negativos), definido como a combinação da probabilidade de um acontecimento e das suas consequências (ISO/IEC Guide 73) ligado às atividades econômicas que usam bens ambientais e particularmente àquelas que usam os recursos naturais destinados à transformação de produtos ou serviços. Com efeito.

Como lembra Helena Mateus Jerónimo ${ }^{24}$, reconceitualizado por autores como Patrick Lagadec (1981) ou Ulrich Beck (1992 [1986]), circunscrito a desenvolvimentos tecnológicos com impactos potencialmente catastróficos no autor francês ou estendido à caracterização das sociedades dos nossos dias como no sociólogo alemão, o conceito de risco tem o engenho de ter trazido para as ciências sociais os novos perigos ambientais introduzidos pela tecnologia. Tal como foi popularizado pela obra Risk Society de Beck, o conceito de risco tem igualmente o mérito de analisar as mudanças na natureza das ameaças atuais: são qualitativamente diferentes das existentes em épocas históricas anteriores quanto à sua capacidade de impacto no ecossistema e de aniquilamento da espécie humana, envolvem dinâmicas até agora desconhecidas e são o produto das ações e das decisões humanas que se concretizam através do complexo científico-tecnológico-industrial.

Por outro lado, observando que "Risk refers to uncertainty about and severity of the events and consequences (or outcomes) of an activity with respect to something that humans value", para usar a sugestão do conceito de risco de Terje Aven e Ortwin Renn ${ }^{25}$, cuida-se, a rigor, de estabelecer uma verdadeira avaliação vinculada

24 JERÓNIMO, Helena Mateus Riscos, incertezas e acidentes: enfrentando problemas tecnocientíficos São Paulo; Fapesp/USP 2011.

25 AVEN, Terje; RENN, Ortwin Risk Management and Governance. Concepts, Guidelines and Applications. Berlin: 
à administração de probabilidades de perigo ligada à incerteza na ciência, como um dos elementos integrantes do processo de conhecimento e sua avaliação e por via de consequência como "parte inerente do método científico e, portanto, um elemento inerente da previsão científica", conforme ensinamentos de Palmer e Hardaker ${ }^{26}$.

Assim, conforme estabelecido no RE 627189, referido princípio exige que o estado analise os riscos, avalie os custos das medidas de prevenção e, ao final, execute as ações necessárias, as quais serão decorrentes de "decisões universais, não discriminatórias, motivadas, coerentes e proporcionais", conforme aprimorada descrição usada pelo STF.

Verifica-se, pois, salvo melhor juízo, que o princípio da precaução, no âmbito do contexto em que foi interpretado pelo Supremo Tribunal Federal no RE 627189, procurou aperfeiçoar a satisfatória compreensão do princípio constitucional econômico da defesa do meio ambiente (Art. 170, VI), particularmente em face do "tratamento diferenciado conforme o impacto ambiental dos produtos e serviços e de seus processos de elaboração e prestação".

Assim estabeleceu na verdade o STF, em face das incumbências atribuídas constitucionalmente ao Poder Público no âmbito do direito constitucional ambiental, um verdadeiro novo conteúdo exigível para instalação de obra ou atividade potencialmente causadora de significativa degradação do meio ambiente, a saber, um conteúdo sempre exigível no plano da elaboração dos estudos prévios de impacto ambiental (art. 225, parágrafo $1^{\circ}, \mathrm{IV}$ ).

\section{O PRINCÍPIO DA PRECAUÇÃO E O NOVO CONTEÚDO EXIGÍVEL NO EPIA (ART.225, PARÁGRAFO 10, IV DA CF) PARA INSTALAÇÃO DE OBRA OU ATIVIDADE POTENCIALMENTE CAUSADORA DE SIGNIFICATIVA DEGRADAÇÃO DO MEIO AMBIENTE.}

A partir do RE 627189, salvo melhor juízo, o Poder Público, em face da incumbência que Ihe foi determinada pelo Art. 225, parágrafo $1^{\circ}$, IV, deverá analisar os riscos, avaliar os custos das medidas de prevenção e, ao final, executar as ações necessárias, as quais serão decorrentes de "decisões universais, não

PALMER T N HARDAKER P J Handling uncertainty in science Publicado em 31 de outubro de 2011 . DOI: 10.1098 / rsta.2011.0280 
discriminatórias, motivadas, coerentes e proporcionais", como procedimento de gestão de riscos obrigatório nas atividades econômicas vinculadas ao meio ambiente natural/recursos naturais.

Trata-se, por via de consequência de análise qualitativa e quantitativa, que evidentemente não se reveste de caráter absoluto, a ser aplicada sempre que existirem incertezas científicas sobre a possibilidade de um produto, evento ou serviço desequilibrar o meio ambiente ou atingir a saúde dos cidadãos, tudo com a finalidade de balizar as atividades econômica exercidas em harmonia com os princípios destinados a tornar efetiva a proteção ao meio ambiente.

\section{CONSIDERAÇÕES FINAIS}

Estabelecido em contexto específico da saúde ambiental, conforme demonstrado no presente trabalho, mas devendonecessariamenteserinterpretado em face do sistema econômico capitalista absorvido pela Constituição Federal e reconhecido pelo Supremo Tribunal Federal, o denominado princípio da precaução, entendido no contexto do RE 627189 como "critério de gestão de risco a ser aplicado sempre que existirem incertezas científicas sobre a possibilidade de um produto, evento ou serviço desequilibrar o meio ambiente ou atingir a saúde dos cidadãos, o que exige que o estado analise os riscos, avalie os custos das medidas de prevenção e, ao final, execute as ações necessárias, as quais serão decorrentes de decisões universais, não discriminatórias, motivadas, coerentes e proporcionais", passa a ter particular relevância em face das atividades econômicas que usam bens ambientais e particularmente àquelas que usam os recursos naturais destinados à transformação de produtos ou serviços. Referido princípio, ao exigir que o Poder Público analise os riscos, avalie os custos das medidas de prevenção e, ao final, execute as ações necessárias, as quais serão decorrentes de "decisões universais, não discriminatórias, motivadas, coerentes e proporcionais", acaba por estabelecer um verdadeiro novo conteúdo exigível para instalação de obra ou atividade potencialmente causadora de significativa degradação do meio ambiente, a saber, um conteúdo sempre exigível no plano da elaboração dos estudos prévios de impacto ambiental (art. 225, parágrafo $1^{\circ}$, IV) com a finalidade de balizar as atividades econômicas exercidas em harmonia com os princípios destinados a tornar efetiva a proteção ao meio ambiente. 


\section{REFERÊNCIAS DAS FONTES CITADAS}

ACCIOLY, SILVA e CASELLA Manual de Direito Internacional Público São Paulo; Saraiva, 2009.

ANCONA LOPES, Teresa Princípio da Precaução e Evolução da Responsabilidade Civil, Tese para Concurso de Professor Titular de Direito Civil da Faculdade de Direito da Universidade de São Paulo, 2008.

AVEN, Terje; RENN, Ortwin Risk Management and Governance. Concepts, Guidelines and Applications. Berlin: Springer,2010

FIORILLO, Celso Antonio Pacheco. Curso de Direito Ambiental Brasileiro. São Paulo: Editora Saraiva 2017

FIORILLO, Celso Antonio Pacheco Curso de Direito Ambiental Brasileiro São Paulo : Editora Saraiva 2000.

FIORILLO, Celso Antonio Pacheco; FERREIRA, Renata Marques.Tutela Constitucional da Defesa do Meio Ambiente como princípio da atividade econômica em face do denominado desenvolvimento sustentável. Novos Estudos Jurídicos, [S.I.], v. 22, n. 2, p. 461-488, ago. 2017. ISSN 2175-0491.

FIORILLO, Celso Antonio Pacheco FERREIRA, Renata Marques Tutela Jurídica do Patrimônio Cultural Brasileiro em face do Direito Ambiental Constitucional Rio de Janeiro: Lumen Juris,2018.

FIORILLO, Celso Antonio Pacheco. O Marco Civil da Internet e o Meio Ambiente Digital na Sociedade da Informação, São Paulo: Saraiva, 2015.

FIORILLO, Celso Antonio Pacheco. Princípios constitucionais do direito da sociedade da informação, São Paulo: Saraiva, 2014.

FIORILLO, Celso Antonio Pacheco. Crimes no Meio Ambiente Digital em face da Sociedade da Informação. São Paulo: Ed. Saraiva, 2016.

JERÓNIMO, Helena Mateus Riscos, incertezas e acidentes: enfrentando problemas tecnocientíficos São Paulo; Fapesp/USP 2011.

LEITE, Antonio Dias Leite A Economia Brasileira - de onde viemos e onde estamos". Rio de Janeiro: Elsevier,2011.

MELLO FILHO, José Celso Constituição Federal Anotada São Paulo; Editora Saraiva, 1986.

MIRANDA, Pontes Comentários à Constituição de 1967 com a emenda número 1 de 1969. Rio de Janeiro: Forense, 1967.

MORAES, Alexandre Direito Constitucional São Paulo: Atlas, 2011. 
NERY Junior,Nelson Constituição Federal comentada e legislação constitucional São Paulo: Revista dos Tribunais, 2009.

PALMER T N HARDAKER P J Handling uncertainty in science Publicado em 31 de outubro de 2011 . DOI: 10.1098 / rsta.2011.0280

SANDRONI, Paulo Novíssimo Dicionário de Economia. São Paulo: Editora Best Seller, 1999.

SANDRONI, Paulo Sandroni. Dicionário de Economia do Século XXI. Rio de Janeiro/São Paulo, Editora Record, 2005

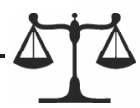

Recebido em: dezembro/2017

Aprovado em: junho/2018 